\title{
The expression of Beclin-1 in testicular tissues of non-obstructive azoospermia patients and its predictive value in sperm retrieval rate
}

\author{
Liang Zhou ${ }^{1,2,3 \#}$, Mo-Qi Lv ${ }^{1 \#}$, Pan Ge ${ }^{1}$, Yan-Qi Yang ${ }^{1}$, Da-Lin He ${ }^{3}$, Hai-Xu Wang ${ }^{1}$, Dang-Xia Zhou ${ }^{1}$ \\ ${ }^{1}$ Department of Pathology, Medical School, Xi'an Jiaotong University, Xi'an, China; ${ }^{2}$ Assisted Reproduction Center, Northwest Women and \\ Children's Hospital, Xi'an, China; ${ }^{3}$ Urology Department, First Affiliated Hospital, Xi'an Jiaotong University, Xi'an, China \\ Contributions: (I) Conception and design: DX Zhou, DL He, MQ Lv; (II) Administrative support: HX Wang; (III) Provision of study materials or \\ patients: L Zhou; (IV) Collection and assembly of data: L Zhou, P Ge; (V) Data analysis and interpretation: MQ Lv, YQ Yang; (VI) Manuscript \\ writing: All authors; (VII) Final approval of manuscript: All authors. \\ \#These authors contributed equally to this work. \\ Correspondence to: Dang-Xia Zhou. Department of Pathology, Medical School, Xi'an Jiaotong University, 76 Yanta West Road, Xi'an 710061 , China. \\ Email: zdxtougao@163.com.
}

Background: Beclin-1 is an autophagy gene and higher levels suggest mammalian testicular damage. Our study aims at exploring the role of Beclin-1 in non-obstructive azoospermia (NOA) patients and clarifying the predictive value of Beclin-1for sperm retrieval in microdissection testicular sperm extraction (micro-TESE).

Methods: In the present study, 62 NOA patients were finally recruited. Serum hormone including luteinizing hormone (LH), follicle-stimulating hormone (FSH), estradiol II (E2), testosterone (T) and prolactin (PRL), as well as testicular volume were measured. Testicular histopathology was diagnosed by two independent pathologists. The expression of Beclin-1 was detected by real-time PCR in testicular tissue.

Results: Our study illustrated that Beclin-1 was differently expressed in three pathological types of NOA. Compared with hypospermatogenesis (HS, $\mathrm{P}=0.002$ ) or maturation arrest (MA, $\mathrm{P}=0.049$ ), Beclin-1 showed significantly up-regulated in Sertoli cell-only syndrome (SCOS) group. Moreover, Beclin-1 expression was obviously positive related with serum $\mathrm{LH}$ ( $\mathrm{rho}=0.269, \mathrm{P}=0.036$ ), meanwhile significantly negative correlation with testicular volume (rho $=-0.370, \mathrm{P}=0.003$ ), serum $\mathrm{T}$ (rho $=-0.326, \mathrm{P}=0.010$ ), Johnsen score (rho $=-0.318, \mathrm{P}=0.012$ ), and pathologic type ( $\mathrm{rho}=-0.452, \mathrm{P}<0.001)$. Furthermore, a logistic regression model demonstrated that Beclin-1 is an important predictor of failed sperm retrieval $(\mathrm{OR}=0.001, \mathrm{P}=0.007)$, which exhibited a pretty AUC =78.6 ( $\mathrm{P}=0.001)$.

Conclusions: Beclin-1 may play a critical role in spermatogenesis. Elevated Beclin-1 may be obviously associated with lower chances of positive sperm retrieval.

Keywords: Beclin-1; spermatogenesis; non-obstructive azoospermia (NOA); autophagy; testicular sperm retrieval

Submitted Apr 15, 2021. Accepted for publication Jun 25, 2021.

doi: $10.21037 /$ tau-21-320

View this article at: https://dx.doi.org/10.21037/tau-21-320

\section{Introduction}

Human infertility is a healthcare problem that has a worldwide impact (1). Currently, male factor infertility is increasing and accounts for about half of all infertility cases $(2,3)$. Non-obstructive azoospermia (NOA) is featured by entirely spermatozoa deficiency in semen $(4,5)$. Approximately $1 \%$ of males or $10 \%$ of infertile males are diagnosed as NOA (6). NOA is a multifactorial disorder and presents with diverse phenotypes (6-8). However, up to now, its molecular pathogenesis remains undefined. 
Since the first successful surgical sperm retrieval combination with intracytoplasmic sperm injection (ICSI) made NOA patients to father children in 1994, sperm retrieval after microdissection testicular sperm extraction (micro-TESE) and in vitro fertilization using ICSI is now the first-line treatment for NOA. Remarkably, approximately $50 \%$ of infertile patients remain unsuccessful in sperm retrieval (9). A failed micro-TESE brings financial, physical, and emotional burdens for the infertile couple. However, so far, no indicators could accurately predict a positive outcome of sperm retrieval. Therefore, the challenge, however, is not only to improve the spermatogenesis function, but also to discover biomarkers for successful testicular sperm retrieval in NOA patients.

Beclin-1, located at chromosome $17 \mathrm{q} 21$ in humans, is the mammalian homolog of the yeast Autophagy-related gene 6 (Atg6) (10). Autophagy has recently been reported to be involved in spermatogenesis and fertilization (11-13). Higher levels of Beclin-1, one of the important autophagy related genes (14), is reported to suggest mammalian testicular damage. For instance, Huang et al. indicated Aflatoxin B1 induced testicular damage and promoted autophagy by increasing the expression of Beclin-1, LC3 and Atg5 in mice testis (15). The results of Wang et al. showed that cadmium accumulates caused testicular injury by increasing autophagy-related protein Beclin1 and LC3 (16). However, so far, the associations between Beclin-1 and infertility remain unknown. Hence, this study was conducted to find some track. We present the following article in accordance with the STARD reporting checklist (available at https://dx.doi.org/10.21037/tau-21-320).

\section{Methods}

\section{Subjects}

In the present research, both researchers and the data analysts are in blind. A consecutive series of NOA subjects were selected from patients attending the infertility clinic in Assisted Reproduction Center, Northwest women and children's Hospital (Xi'an, Shaanxi, China) who had a history of infertility of no less than 12 months. Written informed consent forms were obtained from all subjects. Three times semen analyses were conducted after 3-7 days abstinence. Patients with history of chronic diseases, karyotype abnormalities, microdeletions of AZF region on $\mathrm{Y}$ chromosome and pelvic/spinal injuries were excluded. This study was conducted in accordance with the Declaration of Helsinki (as revised in 2013) and was approved by the Institutional Ethics Committee of Xi'an Jiaotong University (No. 20180817).

\section{Serum bormone determination}

Luteinizing hormone (LH), follicle-stimulating hormone (FSH), estradiol II (E2), serum testosterone (T) and prolactin (PRL) were detected from Blood samples of each patient according to manufacture instruction by using commercial kits from Roche Biology Company.

\section{Testicular sperm retrieval}

The micro-TESE surgery for each patient was conducted by an experienced surgeon. Volume of each testicular was measured in the standard surgery room. Then, a longitudinal incision on the tunica albuginea of the testis was cut to reveal the seminiferous tubules under the professional operating microscope. Tubules with full appearing and opaque, which have possible sperm production, were gently dissected and placed in a petri dish. An experienced embryologist dissected the seminiferous tubules and assessed the presence of sperm with the help of expert microscope. The positive result was confirmed when at least one sperm was found. Thereafter, a large fragment of testicular tissue samples of about $8 \times 4 \times 3 \mathrm{~mm}^{3}$ was cut out, no matter whether the sperm was harvested successfully.

\section{Histopathological examination and fohnsen score}

For histological examination, testicular tissue samples were firstly fixed with Bouin's solution for 24 hours and embedded with paraffin. Then, the slides were stained using Hematoxylin and Eosin solution (HE). Afterwards, all the slides were observed under the microscope by two pathologists. All the pathologic diagnosis were classified into hypospermatogenesis (HS), maturation arrest (MA), and Sertoli-cell-only (SCOS). HS was diagnosed as reduced spermtogeneis with all germ cell types present. MA was defined as premature arrest of spermatogenesis. SCOS was referred to complete deficiency of germ cells. Additionally, the level of spermatogenesis of each testicular sample was measured based on the Johnsen score system (17).

\section{$R N A$ extraction}

Total RNA in testicular tissue samples was extracted by 
Table 1 Clinical characteristics of NOA patients

\begin{tabular}{|c|c|c|c|c|}
\hline Clinical characteristics & HS $(n=13)$ & $\mathrm{MA}(\mathrm{n}=7)$ & $\operatorname{scos}(n=42)$ & $P$ value \\
\hline Testicular volume (mL) & $10.92 \pm 3.28$ & $8.43 \pm 3.64$ & $7.09 \pm 3.03$ & $<0.001^{*}$ \\
\hline $\mathrm{FSH}(\mathrm{mlU} / \mathrm{mL})$ & $10.52 \pm 7.74$ & $18.91 \pm 8.27$ & $20.86 \pm 6.20$ & $<0.001^{\star}$ \\
\hline $\mathrm{LH}(\mathrm{mlU} / \mathrm{mL})$ & $6.03 \pm 3.49$ & $8.01 \pm 2.51$ & $8.78 \pm 2.87$ & $0.028^{*}$ \\
\hline $\mathrm{E} 2(\mathrm{pg} / \mathrm{mL})$ & $28.79 \pm 18.78$ & $24.95 \pm 7.99$ & $27.61 \pm 11.59$ & 0.842 \\
\hline $\mathrm{T}(\mathrm{ng} / \mathrm{dL})$ & $391.32 \pm 177.76$ & $294.85 \pm 74.61$ & $356.37 \pm 169.31$ & 0.469 \\
\hline
\end{tabular}

*, $\mathrm{P}<0.05$, compared among different groups. NOA, non-obstructive azoospermia; HS, hypospermatogenesis; MA, maturation arrest; SCOS, Sertoli cell-only syndrome; FSH, follicle-stimulating hormone; LH, luteinizing hormone; PRL, prolactin; E2,estradiol II; T, testosterone.

RNA Extraction Kit (Takara, Japan). Then RNA was transferred into cDNA Synthesis Kit (Bio-Rad, USA) for next PCR analysis.

\section{Real-time polymerase chain reaction (real-time PCR)}

Real-time PCR analysis was performed using SYBR Green SuperMix Kit (Bio-Rad, USA), following the manufacturer's instructions. The forward primer of Beclin-1 was 5'-AGCTGCCGTTATACTGTTCTG-3', and the reverse was 5'-ACTGCCTCCTGTGTCTTCAATCTT-3'. Meanwhile, the forward primer of housekeeping gene $\beta$-actin was 5'-CATGTACGTTGCTATCCAGGC-3', and the reverse was 5'-CTCCTTAATGTCACGCACGAT-3'. The real-time PCR conditions were conducted by Bio-Rad realtime PCR analyzer (Bio-Rad, USA). The reaction processes were detailedly described in our previous study (18). Each sample was detected in triplicate, and the mean Ct (cycle threshold) value was used to analyze the relative expression of Beclin-1 through the comparative $2^{-\Delta \Delta \mathrm{Ct}}$ method.

\section{Statistical analysis}

Normality of all the data were tested, and the data with skewed distribution were transformed into normally distributed through the cubed root transformation (18). First, the relative expressions of Beclin-1 among three different pathological types of NOA were evaluated using one-way analysis of variance (ANOVA). Thereafter, the correlations between the relative expression of Beclin-1and the clinical parameters such as age, testicular volume, levels of serum hormone (including LH, FSH, E2, T and PRL), and Johnsen score were estimated through Spearman's correlation test. Additionally, univariate and multivariable logistic regression analysis were performed to detect influence factors associated with successful sperm retrieval. Considering that pathologic types are ranked data, we score HS as 3, MA as 2, and SCOS as 1 in the present study. Finally, the receiver operating characteristic (ROC) curve analysis was conducted to calculate the area under the curve (AUC) and the optimal cutoff value (Youden's index) was predicted for the likelihood of successful sperm retrieval.

All statistical analyses were conducted by SPSS statistical software version 18.0 (SPSS Inc., IL, USA).

\section{Results}

\section{Clinical characteristics of NOA patients}

A total of 62 NOA were involved. According to the results of histological examination, the $62 \mathrm{NOA}$ patients consists of 13 HS (20.97\%), 7 MA (11.29\%) and 42 SCOS (67.74\%).

The clinical characteristics of 62 NOA patients were summarized in Table 1. As shown in Table 1, testicular volume $(\mathrm{P}<0.001)$, serum FSH $(\mathrm{P}<0.001)$ and serum $\mathrm{LH}$ $(\mathrm{P}=0.028)$ were significantly aberrantly expressed among three different pathological types of NOA (SCOS, MA, HS). SCOS group demonstrated smaller testicular volumes, higher serum FSH level and higher serum LH level. Age, level of serum T, E2 and PRL showed no statistic differences among HS, MA and SCOS groups. 


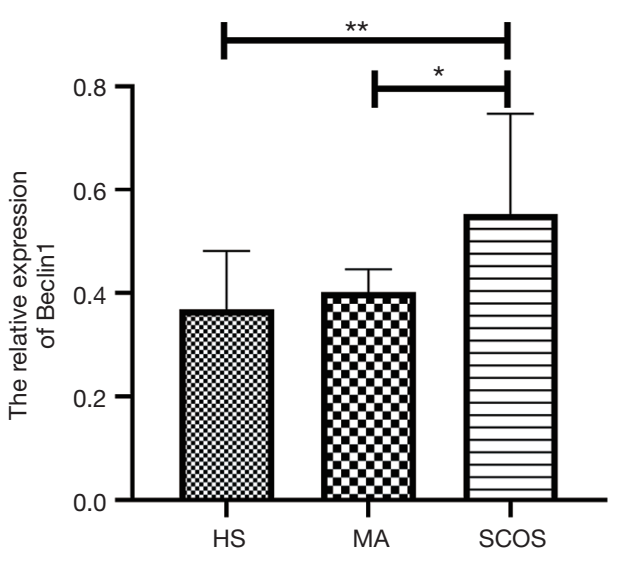

Figure 1 The relative expression of Beclin-1 in three different pathological types of NOA patients. **, $\mathrm{P}<0.01$; * $\mathrm{P}<0.05$. NOA, non-obstructive azoospermia; HS, hypospermatogenesis; MA, maturation arrest; SCOS, Sertoli cell-only syndrome.

Table 2 Associations between Beclin-1 expression and clinicpathological parameters of NOA patients

\begin{tabular}{lcc}
\hline \multirow{2}{*}{ Clinicopathological parameters } & \multicolumn{2}{c}{ Beclin-1 expression } \\
\cline { 2 - 3 } & rho & $\mathrm{P}$ \\
\hline Age $(\mathrm{y})$ & -0.102 & 0.432 \\
Testicular volume $(\mathrm{mL})$ & -0.37 & $0.003^{\star}$ \\
FSH $(\mathrm{mlU} / \mathrm{mL})$ & 0.249 & 0.053 \\
LH $(\mathrm{mlU} / \mathrm{mL})$ & 0.269 & $0.036^{*}$ \\
PRL $(\mathrm{ng} / \mathrm{mL})$ & -0.114 & 0.394 \\
E2 $(\mathrm{pg} / \mathrm{mL})$ & 0.023 & 0.865 \\
T $(\mathrm{ng} / \mathrm{dL})$ & -0.326 & $0.010^{*}$ \\
Pathological type & -0.452 & $<0.001^{*}$ \\
Johnsen Score & -0.318 & $0.012^{*}$ \\
\hline
\end{tabular}

${ }^{*}, \mathrm{P}<0.05$, significant correlation. NOA, non-obstructive azoospermia; FSH, follicle-stimulating hormone; LH, luteinizing hormone; PRL, prolactin; E2, estradiol II; T, testosterone; rho: spearman correlation coefficient.

\section{Differential expression of Beclin-1 in three different pathological types of NOA}

Figure 1 revealed the Beclin-1 expression profile in three pathological types of NOA patients. As it shown, Beclin-1 mRNA expression level was obviously up-regulated in SCOS group when compared to HS group $(\mathrm{P}=0.002)$ and MA group $(\mathrm{P}=0.049)$.

\section{Associations of Beclin-1 with clinical parameters of NOA}

The correlations between Beclin-1 and the clinical parameters were shown in Table 2. The relative expression of Beclin-1 in testicular tissue was significantly positively correlated with serum LH (rho $=0.269, \mathrm{P}=0.036$ ), meanwhile obviously negatively correlated with testicular volume (rho $=-0.370$, $\mathrm{P}=0.003$ ), serum $\mathrm{T}$ (rho $=-0.326, \mathrm{P}=0.010$ ), Johnsen score (rho $=-0.318, \mathrm{P}=0.012)$ and pathologic type $($ rho $=-0.452, \mathrm{P}<0.001)$ (we score HS as 3, MA as 2, and SCOS as 1).

\section{The predictive value of Beclin-1 for testicular sperm retrieval}

We used univariate and multivariable logistic regression analysis to detect the predictive factors related with testicular sperm retrieval. At first, as shown in Table 3, in univariate logistic analysis, we included all parameters such as age, testicular volume, serum FSH, LH, PRL, E2, T, Johnsen score, and the relative expression of Beclin-1 for analysis. The results showed that the relative expression of Beclin-1 (OR $=0.001 ; 95 \% \mathrm{CI}, 0.001$ to $0.111 ; \mathrm{P}=0.007$ ), serum FSH (OR $=0.901 ; 95 \% \mathrm{CI}, 0.830$ to $0.979 ; \mathrm{P}=0.014$ ), and serum LH $(\mathrm{OR}=0.797 ; 95 \% \mathrm{CI}, 0.646$ to 0.984 ; $\mathrm{P}=0.035)$ were the negative predictor for sperm retrieval. To the contrary, Johnsen score $(\mathrm{OR}=1.877 ; 95 \% \mathrm{CI}$, 1.316 to $2.676 ; \mathrm{P}=0.001$ ) was favorable predictor for sperm retrieval. Moreover, ROC curve analysis exhibited that the relative expression of Beclin-1 $(\mathrm{AUC}=78.6 \%, \mathrm{P}=0.001$; Figure $2 A$ ) and $\mathrm{FSH}(\mathrm{AUC}=70.1 \%, \mathrm{P}=0.018$; Figure $2 A$ ) has statistically significant effect on positive sperm retrieval, respectively. Remarkably, the relative expression of Beclin-1 showed a cutoff value of 0.428 , with a sensitivity of 0.556 and specificity of 0.860 for predicted likelihood. Other parameters demonstrated no meaningful predictive value.

Next, multivariate logistic regression was involved in serum FSH, serum LH, Johnsen score and the relative expression of Beclin-1 which were significantly associated with sperm retrieval in univariate logistic analysis Only the relative expression of Beclin-1 (OR $=0.001 ; 95 \%$ CI, 0.001 to $0.707 ; \mathrm{P}=0.039)$ and Johnsen score $(\mathrm{OR}=1.632 ; 95 \% \mathrm{CI}$, 1.043 to $2.554 ; \mathrm{P}=0.032$ ) were still significantly associated with successful sperm retrieval (Table 3). Further ROC curve analysis indicated that the model with combination of the relative expression of Beclin-1 and Johnsen score showed a better predictive value (AUC $=84.8 \%, \mathrm{P}<0.001$; Figure $2 B$ ). In this prediction formula, $\mathrm{A}=1.035-6.970 \times$ Beclin-1 
Table 3 Univariate and multivariate logistic analyses of the contributing factors for successful sperm retrieval in NOA patients

\begin{tabular}{|c|c|c|c|c|c|c|c|c|}
\hline \multirow{3}{*}{ Variable } & \multicolumn{4}{|c|}{ Univariate logistic analysis } & \multicolumn{4}{|c|}{ Multivariate logistic analysis } \\
\hline & \multirow{2}{*}{ OR } & \multicolumn{2}{|c|}{$95 \% \mathrm{Cl}$} & \multirow{2}{*}{$P$ value } & \multirow{2}{*}{ OR } & \multicolumn{2}{|c|}{$95 \% \mathrm{Cl}$} & \multirow{2}{*}{$P$ value } \\
\hline & & Low & High & & & Low & High & \\
\hline Age $(y)$ & 1.025 & 0.918 & 1.145 & 0.663 & - & - & - & - \\
\hline Testicular volume (mL) & 1.167 & 0.987 & 1.379 & 0.071 & - & - & - & - \\
\hline $\mathrm{LH}(\mathrm{mlU} / \mathrm{mL})$ & 0.797 & 0.646 & 0.984 & $0.035^{\star}$ & 0.892 & 0.619 & 1.286 & 0.541 \\
\hline $\mathrm{PRL}(\mathrm{ng} / \mathrm{mL})$ & 1.018 & 0.951 & 1.089 & 0.609 & - & - & - & - \\
\hline E2 $(p g / m L)$ & 0.969 & 0.918 & 1.023 & 0.260 & - & - & - & - \\
\hline $\mathrm{T}(\mathrm{ng} / \mathrm{dL})$ & 1.002 & 0.998 & 1.005 & 0.290 & - & - & - & - \\
\hline
\end{tabular}

Considering that Johnsen score and pathological diagnostic types existed significant colinearity, we decided to add the Johnsen score (ranked data) but not pathological diagnostic types (categorical data) in our logistic regression models. ${ }^{*}, \mathrm{P}<0.05$. NOA, non-obstructive azoospermia; FSH, follicle-stimulating hormone; LH, luteinizing hormone; PRL, prolactin; E2, estradiol II; T, testosterone; OR, odds ratio; $\mathrm{Cl}$, confidence interval.
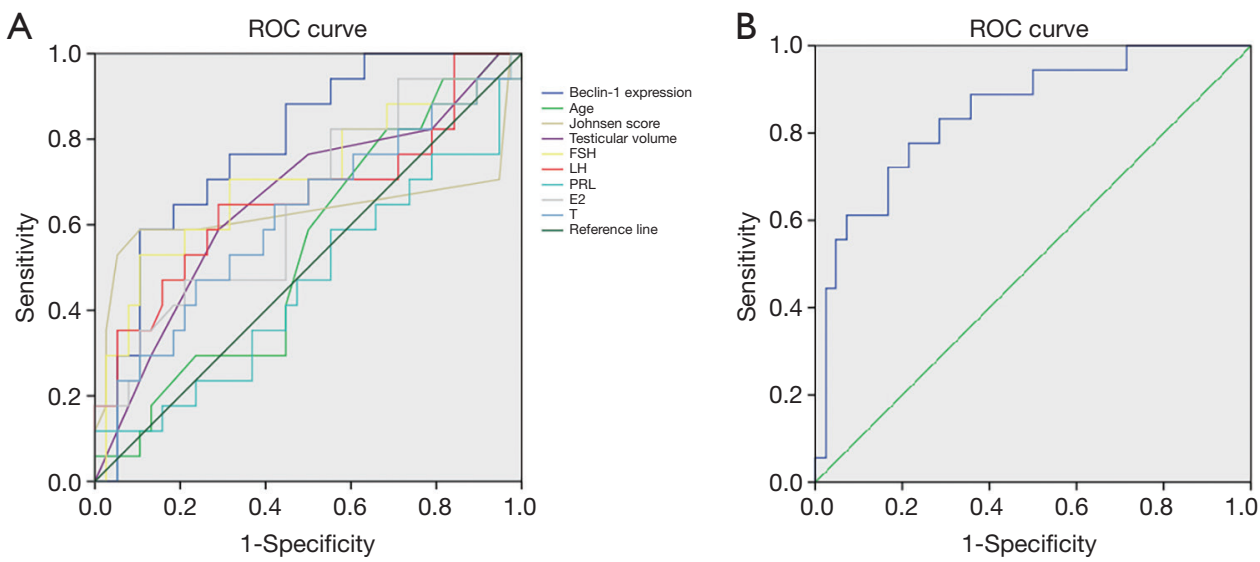

Figure 2 ROC curves of the univariate prediction models in NOA patients. (A) Beclin-1 (AUC =78.6\%, P=0.001), Age (AUC =54.2\%, $\mathrm{P}=0.623$ ), Johnsen score ( $\mathrm{AUC}=63.1 \%, \mathrm{P}=0.124)$, Testicular volume (AUC =65.8\%, P=0.063), FSH (AUC =70.1\%, P=0.018), LH (AUC =66.2\%, P=0.057), PRL (AUC =46.1\%, P=0.649), E2 (AUC =64.7\%, P=0.084), T (AUC =61.3\%, P=0.184); (B) the combination between Beclin-1 expression and Johnsen score (AUC =84.8\%, P<0.001). ROC, receiver operating characteristic; NOA, non-obstructive azoospermia; FSH, follicle-stimulating hormone; LH, luteinizing hormone; PRL, prolactin; E2, estradiol II; T, testosterone.

expression $+0.490 \times$ Johnsen score.

\section{Discussion}

The results firstly demonstrated that Beclin-1 were differently expressed in three pathological types of NOA, and Beclin-1 showed a higher expression in SCOS group when compared with HS and MA group, respectively. Moreover, its expression was obviously positive correlation with serum LH, meanwhile significantly negative correlation with testicular volume, serum T, Johnsen score and pathologic type. Furthermore, a multivariate analysis demonstrated that Beclin-1 showed inverse relationship with testicular sperm retrieval. The cutoff value was 0.428 , indicating that 
males, whose relative expression of Beclin-1 in testis was no more than 0.428 , will have positive result in sperm retrieval in standard micro-TESE surgery. Our work has laid the foundations to develop Beclin-1 as a promising biomarker for predicting sperm retrieval and diagnosing NOA.

Spermatogenesis is a highly programmed and intricate physiological process which hinges on dynamic balance of spermatogenetic cells (19-21). Autophagy is a self-eating process inducible by nutrient starvation $(22,23)$. Mounting evidence indicates that autophagy is very important for spermatogenesis $(11,24,25)$. Abnormal autophagy might contribute to spermatogenesis failure. For instance, spermatogenetic injury induced by ethanol depends on the activation of autophagy in Sertoli cells (26). Heat lead to mice spermatogenetic cells death also associated with the stir up of autophagy (21). Formaldehyde exposure might trigger excessive autophagy related with spermatogenesis impairment (27).

The present study found that Beclin-1 were significantly up-regulated expressed in SCOS group when compared with HS and MA group, meaning that Beclin-1 has a higher expression in men with more severe histopathology. Beclin-1 is a vital component of PtdIns3 kinase which stirs up autophagy (28). Beclin-1 complex (includes Beclin-1, VPS34, VPS15 and ATG14) also plays the essential roles in autophagy initiation and regulation (14). These interesting results drove us to focus on Beclin-1 related autophagy is valuable in spermatogenesis. This view was consistent with other authors $(11,12)$. Thus, we have reasons to believe that autophagy-related gene Beclin-1 might be very helpful to guide personalized diagnosis and treatment of NOA. Moreover, Beclin-1 expression was also obviously positive correlation with serum LH, meanwhile significantly negative correlation with testicular volume, serum $\mathrm{T}$, Johnsen score and pathologic type. Remarkably, more severe histopathology was reported to associated with higher level of serum LH (29), smaller testicular volume (30), lower level of serum T (31), and lower Johnsen score (32). Higher-expressed Beclin-1 was also correlated with more severe histopathology. Hence, we are not sure that these associations between Beclin-1 and these clinical features may be due to the severity of histopathology rather than Beclin-1 expression. Further studies are expected to explore the role of Beclin-1 in regulating clinical features.

In addition, the results of univariate logistic analysis indicated that Beclin-1, Johnsen score, serum LH, and serum FSH were potential factors for predicting sperm retrieval. The results about the predictive value of serum
FSH and Johnsen score are line with previous studies (30,33,34). For example, Abdel Raheem et al. reported that the Johnsen score $\geq 8$ is the excellent predictor of successful sperm retrieval (33). A meta-analysis of Li et al. summarized that the histopathological type was a meaningful predictor to some extent and most patients with HS may be more likely to get sperm by micro-TESE (30). Guler et al. concluded that FSH is the best predictor of a successful TESE (34).

Moreover, further multivariate logistic analysis additionally disclosures that Beclin-1 and Johnsen score had the most significantly predictive value for predicting sperm retrieval. Beclin-1 was inversely related with successful sperm retrieval, however, Johnsen Score was directly related with successful sperm retrieval. As is known that sperm retrieval rates are primarily associated with pathologic types. Considering that pathologic types are ranked data, we did not add it into our multivariate analysis model. Our result indicated that Beclin-1 and Johnsen score, which had been reported to be related with pathologic types, showed significant predictive value in sperm retrieval. These findings further indicated that Beclin-1 might be vital biomarker for predicting successful sperm retrieval.

Other than the retrospective nature of this study, some non-negligible limitations exist. Firstly, early vs late MA depends on being prior to after meiotic division when the arrest occurs. These are very differing severities of histopathological architecture and should be looked at separately. The present study is limited by the small sample size (7 MA patients). Further study with more MA patients is in needed. Secondly, the subjects of our study are limited in our hospital. Further researches with larger samples from other hospitals or centers are expected to validate our model. Thirdly, the representation of the population is not perfect, which is a common limitation in develop prediction models. Fourthly, the beclin-1 levels in fertile male controls are necessary, and further study are in needed to explore the differential expression of beclin-1 between NOA patients and fertile males, which may lays a foundation for exploring the role and the molecular mechanisms of Beclin-1 in NOA.

\section{Conclusions}

In summary, this study firstly demonstrated the expression profile and predictive value of Beclin-1 in NOA, indicating that Beclin-1 might act a vital role in spermatogenesis and it might be a important bio-marker for future prevention and therapy of NOA. However, there is still a long way to go in 
the exploration of detailed molecular mechanism.

\section{Acknowledgments}

We would like to thank Yixin Lee for his help in polishing our paper.

Funding: This research was financially supported by National Natural Science Funding of China (No. 81673224; 81273018; 30700654), Natural Science Funding of Shaanxi Province (No. 2019JM029; 2015JM8436), Science Funding of Health Department, Shaanxi Province (No. 2012D58), the Fundamental Research Funds for the Central University (No. XJJ 2011024) and the Project of Independent Innovative Experiment for Postgraduates in medicine in Xi'an Jiaotong University (No. YJSCX-2017-007 and YJSCX-2018-011).

\section{Footnote}

Reporting Checklist: The authors have completed the STARD reporting checklist. Available at https://dx.doi. org/10.21037/tau-21-320

Data Sharing Statement: Available at https://dx.doi. org/10.21037/tau-21-320

Peer Review File: Available at https://dx.doi.org/10.21037/ tau-21-320

Conflicts of Interest: All authors have completed the ICMJE uniform disclosure form (available at https://dx.doi. org/10.21037/tau-21-320). The authors have no conflicts of interest to declare.

Ethical Statement: The authors are accountable for all aspects of the work in ensuring that questions related to the accuracy or integrity of any part of the work are appropriately investigated and resolved. This study was conducted in accordance with the Declaration of Helsinki (as revised in 2013) and was approved by the Institutional Ethics Committee of Xi'an Jiaotong University (No. 20180817). All patients signed informed consent forms.

Open Access Statement: This is an Open Access article distributed in accordance with the Creative Commons Attribution-NonCommercial-NoDerivs 4.0 International License (CC BY-NC-ND 4.0), which permits the non- commercial replication and distribution of the article with the strict proviso that no changes or edits are made and the original work is properly cited (including links to both the formal publication through the relevant DOI and the license). See: https://creativecommons.org/licenses/by-nc-nd/4.0/.

\section{References}

1. Jedidi I, Ouchari M, Yin Q. Sex chromosomes-linked single-gene disorders involved in human infertility. Eur J Med Genet 2019;62:103560.

2. Luján S, Caroppo E, Niederberger C, et al. Sperm DNA Methylation Epimutation Biomarkers for Male Infertility and FSH Therapeutic Responsiveness. Sci Rep 2019;9:16786.

3. Ferlin A, Foresta C. New genetic markers for male infertility. Curr Opin Obstet Gynecol 2014;26:193-8.

4. Deruyver Y, Vanderschueren D, Van der Aa F. Outcome of microdissection TESE compared with conventional TESE in non-obstructive azoospermia: a systematic review. Andrology 2014;2:20-4.

5. Nakamura S, Miyado M, Saito K, et al. Next-generation sequencing for patients with non-obstructive azoospermia: implications for significant roles of monogenic/oligogenic mutations. Andrology 2017;5:824-31.

6. Ezeh UI, Moore HD, Cooke ID. A prospective study of multiple needle biopsies versus a single open biopsy for testicular sperm extraction in men with non-obstructive azoospermia. Hum Reprod 1998;13:3075-80.

7. Jaiswal D, Trivedi S, Agrawal NK, et al. Dysregulation of apoptotic pathway candidate genes and proteins in infertile azoospermia patients. Fertil Steril 2015;104:736-43.e6.

8. Bernie AM, Shah K, Halpern JA, et al. Outcomes of microdissection testicular sperm extraction in men with nonobstructive azoospermia due to maturation arrest. Fertil Steril 2015;104:569-73.e1.

9. Oka S, Shiraishi K, Matsuyama H. Effects of human chorionic gonadotropin on testicular interstitial tissues in men with non-obstructive azoospermia. Andrology 2017;5:232-9.

10. Cai $M, \mathrm{Hu} Z$, Liu J, et al. Beclin 1 expression in ovarian tissues and its effects on ovarian cancer prognosis. Int J Mol Sci 2014;15:5292-303.

11. Wang H, Wan H, Li X, et al. Atg7 is required for acrosome biogenesis during spermatogenesis in mice. Cell Res 2014;24:852-69.

12. Muniyappa K, Kshirsagar R, Ghodke I. The HORMA domain: an evolutionarily conserved domain discovered in 
chromatin-associated proteins, has unanticipated diverse functions. Gene 2014;545:194-7.

13. Gao H, Khawar MB, Li W. Essential role of autophagy in resource allocation during sexual reproduction. Autophagy 2020;16:18-27.

14. Menon MB, Dhamija S. Beclin 1 Phosphorylation - at the Center of Autophagy Regulation. Front Cell Dev Biol 2018;6:137.

15. Huang W, Cao Z, Zhang J, et al. Aflatoxin B1 promotes autophagy associated with oxidative stress-related PI3K/ AKT/mTOR signaling pathway in mice testis. Environ Pollut 2019;255:113317.

16. Wang YJ, Yan J, Yin F, et al. Role of autophagy in cadmium-induced testicular injury. Hum Exp Toxicol 2017;36:1039-48.

17. Johnsen SG. Testicular biopsy score count--a method for registration of spermatogenesis in human testes: normal values and results in 335 hypogonadal males. Hormones 1970;1:2-25.

18. Lv MQ, Zhou L, Ge P, et al. Over-expression of hsa_ circ_0000116 in patients with non-obstructive azoospermia and its predictive value in testicular sperm retrieval. Andrology 2020;8:1834-43.

19. Krausz C, Riera-Escamilla A. Genetics of male infertility. Nat Rev Urol 2018;15:369-84.

20. Matzuk MM, Lamb DJ. The biology of infertility: research advances and clinical challenges. Nat Med 2008;14:1197-213.

21. Zhang M, Jiang M, Bi Y, et al. Autophagy and apoptosis act as partners to induce germ cell death after heat stress in mice. PLoS One 2012;7:e41412.

22. Hurley JH, Schulman BA. Atomistic autophagy: the structures of cellular self-digestion. Cell 2014;157:300-11.

23. Liu QP, Zhou DX, Lv MQ, et al. Formaldehyde inhalation triggers autophagy in rat lung tissues. Toxicol Ind Health 2018. [Epub ahead of print]. doi: 10.1177/0748233718796347.

24. Hayrabedyan S, Todorova K, Jabeen A, et al. Sertoli cells have a functional NALP3 inflammasome that can

Cite this article as: Zhou L, Lv MQ, Ge P, Yang YQ, He DL, Wang HX, Zhou DX. The expression of Beclin-1 in testicular tissues of non-obstructive azoospermia patients and its predictive value in sperm retrieval rate. Transl Androl Urol 2021;10(8):3267-3274. doi: 10.21037/tau-21-320 modulate autophagy and cytokine production. Sci Rep 2016;6:18896.

25. Fang J, Li DH, Yu XQ, et al. Formaldehyde exposure inhibits the expression of mammalian target of rapamycin in rat testis. Toxicol Ind Health 2016;32:1882-90.

26. Eid N, Ito Y, Otsuki Y. Enhanced mitophagy in Sertoli cells of ethanol-treated rats: morphological evidence and clinical relevance. J Mol Histol 2012;43:71-80.

27. Han SP, Zhou DX, Lin P, et al. Formaldehyde exposure induces autophagy in testicular tissues of adult male rats. Environ Toxicol 2015;30:323-31.

28. He R, Peng J, Yuan P, et al. Divergent roles of BECN1 in LC3 lipidation and autophagosomal function. Autophagy 2015;11:740-7.

29. Babu SR, Sadhnani MD, Swarna M, et al. Evaluation of FSH, LH and testosterone levels in different subgroups of infertile males. Indian J Clin Biochem 2004;19:45-9.

30. Li H, Chen LP, Yang J, et al. Predictive value of FSH, testicular volume, and histopathological findings for the sperm retrieval rate of microdissection TESE in nonobstructive azoospermia: a meta-analysis. Asian J Androl 2018;20:30-6.

31. Lardone MC, Piottante A, Valdevenito R, et al. Histological and hormonal testicular function in oligo/ azoospermic infertile men. Andrologia 2013;45:379-85.

32. Calogero AE, Garofalo MR, Barone N, et al. Spontaneous regression over time of the germinal epithelium in a $\mathrm{Y}$ chromosome-microdeleted patient: Case report. Hum Reprod 2001;16:1845-8.

33. Abdel Raheem A, Garaffa G, Rushwan N, et al. Testicular histopathology as a predictor of a positive sperm retrieval in men with non-obstructive azoospermia. BJU Int 2013;111:492-9.

34. Guler I, Erdem M, Erdem A, et al. Impact of testicular histopathology as a predictor of sperm retrieval and pregnancy outcome in patients with nonobstructive azoospermia: correlation with clinical and hormonal factors. Andrologia 2016;48:765-73. 